San Jose State University

SJSU ScholarWorks

Faculty Publications

Health Science and Recreation

November 2011

\title{
Patients' reports about medical doctors' inquiries on their mental health: Do generational status, ethnicity and mental health/ substance use disorders matter?
}

\author{
Van M. Ta Park \\ San Jose State University, van.ta@sjsu.edu \\ P. Holck \\ University of Hawaii at Manoa \\ T. Chen \\ University of Washington - Seattle Campus \\ N. Zane \\ University of California - Davis
}

Follow this and additional works at: https://scholarworks.sjsu.edu/healthsci_rec_pub

Part of the Medicine and Health Sciences Commons

\section{Recommended Citation}

Van M. Ta Park, P. Holck, T. Chen, and N. Zane. "Patients' reports about medical doctors' inquiries on their mental health: Do generational status, ethnicity and mental health/substance use disorders matter?" Journal of Health Care for the Poor and Underserved (2011): 1369-1386.

This Article is brought to you for free and open access by the Health Science and Recreation at SJSU

ScholarWorks. It has been accepted for inclusion in Faculty Publications by an authorized administrator of SJSU

ScholarWorks. For more information, please contact scholarworks@sjsu.edu. 


\title{
Patients' Reports about Medical Doctors' Inquiries on Their Mental Health: Do Generational Status, Ethnicity and Mental Health/Substance Use Disorders Matter?
}

\author{
Van M. Ta, PhD, MPH \\ Peter Holck, $\mathrm{PhD}, \mathrm{MPH}$ \\ TeChieh Chen, BA \\ Nolan Zane, $\mathrm{PhD}$
}

\begin{abstract}
Immigrants are less likely than others to use mental health $(\mathrm{MH})$ services. Physicians' limited time often precludes inquiry about $\mathrm{MH}$. This study investigated the influence of generational status, ethnicity, and mental/substance use disorders on physicians' inquiries about Asian American (AA) MH. Data from the National Latino and Asian American Study were analyzed $(n=1,853)$. The outcome was past year physician's inquiry regarding $M H$. Results revealed that AA with U.S.-born parents had significantly greater odds compared to AA born outside the U.S. to report that their doctors inquired about their $\mathrm{MH}(\mathrm{OR}=2.18$, 95\% CI: 1.28, 3.73). Past year mental/substance use disorder increased the odds of AA reporting that their doctors inquired about their $\mathrm{MH}(\mathrm{OR}=8.41 ; 95 \% \mathrm{CI}: 3.28,21.66)$. This increase differed by ethnicity, with Chinese less affected than Vietnamese $(\mathrm{OR}=0.17 ; 95 \%$ CI: $0.05,0.59)$. The reasons for these associations warrant further exploration.
\end{abstract}

Key words: Asian Americans, mental health, provider inquiry, generational status.

$\mathrm{P}$ rior research suggests that immigrants are less likely than others in the U.S. to use mental health services. ${ }^{1,2}$ Since $69 \%$ of Asian Americans were not born in the U.S., it is imperative to understand how this population accesses mental health care. ${ }^{3}$ A robust body of literature demonstrates that Asian Americans are unlikely to access

DR. TA is an Assistant Professor in the Department of Health Science at San José State University. Her primary research interest is to address issues related to health and health care disparities, especially among at-risk Asian American and Native Hawaiian/Other Pacific Islander women in the areas of mental health, substance use, and intimate partner violence. DR. HOLCK is a statistical consultant at the University of Hawai' $i$ at Mānoa, whose research interests include data mining and analysis of large public health related databases. MS. CHEN is a Project Director at the Innovative Programs Research Group in the School of Social Work at the University of Washington; her research interests include substance abuse and mental health issues, particularly among ethnic minorities, such as Asian Americans, the homeless, and the military. DR. ZANE is Professor of Psychology and Asian American Studies at the University of California, Davis and Director of the Asian American Center on Disparities Research. He also is the Director of the Asian American Studies Program at UC Davis. Please address correspondence to Van M. Ta, PhD, MPH, Assistant Professor, Department of Health Science, San José State University, One Washington Square, MH 514, San José, CA 95192; (408) 924-2988; van.ta@sjsu.edu. 
mental health services. ${ }^{4-6}$ In a nationally representative sample of Asian-Americans, $34 \%$ of those with a mental health disorder accessed care in the past year, which is a lower rate than the general population. ${ }^{2}$ Despite this, there is a paucity of research investigating the different ways Asian Americans are referred to mental health services. One likely pathway to receiving appropriate mental health care is through a physician's inquiry into a patient's mental health status. In such a medical setting, Asian Americans are prone to expressing mental health symptoms in the form of somatic symptoms. ${ }^{7}$ Though physicians' limited time often prevents inquiry into a patient's mental health, ${ }^{8}$ an argument may be made that such inquiry should become standard when determining a patient's health and well-being for two main reasons. The first reason concerns how health is defined. The World Health Organization (WHO) defines health as "a state of complete physical, mental and social well-being and not merely the absence of disease or infirmity"9[p.1] However, physicians have a number of competing medical concerns to attend to in a limited time; mental health is rarely the sole focus of a medical visit. ${ }^{10,11}$ One may argue that although the WHO's definition of health is widely known, it is not widely applied in U.S. health care settings.

Second, regardless of whether one concurs with the WHO's definition of health, strong evidence exists that a medical doctor's diagnosis of mental health in adults, particularly depression, is integral to their health. Indeed, lack of access to mental health care results in adverse outcomes. ${ }^{12,13}$ The U.S. Preventive Services Task Force recommends that providers screen for depression among adults when staff-assisted depression support is available to assure not only accurate diagnosis but also effective treatment and follow-up. ${ }^{14}$ Both considerations support the notion that medical doctors' inquiries into mental health should become commonplace.

It is important to note, however, the lack of studies examining the question of whether universal screening for mental health leads to relevant treatment. Though there is some lack of agreement or understanding on how to incorporate mental health screening in clinical settings effectively, ${ }^{14,15}$ mental health screenings could lead to more people getting effective mental health care.

Though research about medical doctors' inquiries about Asian Americans' mental health is scant, Asian Americans' likelihood of receiving mental health services has been shown to be influenced by ethnicity, generational status, sex, time spent in the United States, assimilation level, and mental health/substance use diagnosis. ${ }^{2,16-18}$ For example, Barry and Grilo conducted a study of Asian immigrants' willingness to use mental health services if depressed, and of the likelihood of their recommending such services to friends with mental health issues. Willingness to enter treatment or refer others to treatment did not differ by ethnic group (Chinese, Japanese, Korean); however, women and more assimilated individuals were more willing than their counterparts to use mental health services and refer friends to such services. ${ }^{16}$ Additionally, they found the longer people lived in the U.S., the less willing they were to seek treatment. The authors note that while assimilation and time spent in the U.S. are correlated, it is important to consider these two variables separately. In other words, one cannot infer assimilation from time spent in the United States, or vice versa. Time spent in the U.S. is a demographic variable whereas assimilation is tied to acculturation.

People from successive generations are increasingly willing to seek treatment. In a 
Canadian study, Hsu and Alden examined first and second generation Chinese and non-Hispanic White students' willingness to seek mental health treatment for social anxiety. ${ }^{17}$ Regardless of background, participants did not differ in willingness to seek treatment for low and severe social anxiety. However, while first-generation Chinese students did not perceive social anxiety to be less debilitating than did their peers, they were less likely to seek treatment for moderate social anxiety. This indicates that different factors, such as acculturation, influence Asian immigrants' willingness to seek mental health treatment, and should be considered when engaging this population in mental health care.

Medical services as a pathway to mental health services have been briefly studied., ${ }^{8,19}$ One study examined the degree to which primary care doctors were able to recognize psychiatric distress among an ethnically diverse sample, including Asian Americans. ${ }^{19}$ While $42 \%$ of Asian American patients in the studied population displayed psychiatric distress symptoms, the doctors identified only $24 \%$ as being psychiatrically distressed. In contrast, when $47 \%$ of Latino patients had psychiatric distress symptoms the doctors identified $44 \%$ as psychiatrically distressed. Patients with lower acculturation status were less likely to be identified as psychiatrically distressed. Notably, $90 \%$ of Asian American patients experienced language congruence (primarily Chinese) with their Asian American doctors, whereas 65\% of Latino patients had Spanish-speaking Latino doctors.

Research suggests that Asian Americans are underscreened for mental health problems and/or underutilize mental health services. One study examined use of mental health and substance abuse services by Asian American, Native Hawaiian/Other Pacific Islander, and non-Hispanic White mothers. ${ }^{20}$ Results revealed that Asian American mothers who screened positive for depression were significantly less likely than nonHispanic White mothers who also screened positive for depression to report receiving mental health/substance use services. It is plausible that these mothers were not aware of their depression status given that this screening was conducted as part of their participation in a child abuse and neglect prevention program (Healthy Start Program), and did not occur at a medical office. Another study that examined generational status and family cohesion effects on use of mental health services among Asian Americans ${ }^{21}$ indicated that while almost $13 \%$ of participants hae a Diagnostic and Statistical Manual of Mental Disorders, Fourth Edition (DSM-IV) disorder in the past 12 months, less than $9 \%$ received mental health/substance use services. Again, it is plausible that the study participants were not aware of their mental health status given that this screening was conducted as part of their participation in National Latino and Asian American Study (NLAAS), and did not occur at a medical office. These studies suggest that that there is a portion of Asian Americans with unmet mental health treatment needs, but whether this is an issue of treatment engagement or retention versus screening at a medical office is unclear.

Social desirability is also an important concept to consider when thinking about Asian American mental health. Research has shown that ethnic minorities, such as Asian Americans, are more likely than non-Hispanic Whites, African Americans, and Hispanics to respond in socially desirable responsible ways. ${ }^{22}$ Additionally, people that come from more collectivist cultures are more inclined than people from more 
individualistic cultures to score higher on social desirability scales due to a desire to save face and maintain social approval. ${ }^{23}$ Furthermore, previous research included social desirability in their statistical models in their analyses of the NLAAS data, ${ }^{21,24,25}$ the same data source for this paper. Since research suggests that social desirability will be of particular relevance in this population, this variable was included in this study's analyses.

Poverty is an important variable to consider as well. Poverty is defined in terms of household income as well as household size. ${ }^{26}$ (An examination of Asian Americans household income alone artificially inflates Asian Americans socioeconomic status and contributes to the Model Minority Myth. ${ }^{27}$ Briefly, the Model Minority Myth extols stereotypical positive attributes of Asian Americans such as how hard-working and studious the population is without acknowledging the heterogeneity and diverse experiences of the population..$^{28}$ ) Since poverty is a more accurate socioeconomic status indicator, it will be included in this study's analyses.

To the authors' knowledge, studies investigating the roles of generational status, ethnicity, and mental/substance use disorders on self-reported medical doctors' inquiries about Asian American patients' mental health status are nonexistent. Given that recent immigrants are less likely than U.S.-born people to use mental health services, ${ }^{1,2}$ it is hypothesized that recent Asian American immigrants are less likely than U.S. born Asian Americans to be asked about their mental health status. Additionally, there is a larger proportion of Vietnamese (76\%) than of other Asian Americans (i.e., 70\% of Chinese; $68 \%$ of Filipino) who are recent immigrants; ${ }^{3}$ thus, it is hypothesized that Vietnamese are less likely than others to be asked about their mental health status.

Asian Americans comprise diverse ethnic groups and people with varying generation and nativity backgrounds. ${ }^{3,29}$ Findings from this study can provide researchers, practitioners, and consumers a better understanding of the specific needs and priorities of this heterogeneous population in the U.S.

\section{Methods}

Sample. Data were drawn from the National Latino and Asian American Study (NLAAS), a household survey conducted in 2002-03, and restricted to Asian American respondents. The sampling design has been detailed elsewhere. ${ }^{30,31}$ Briefly, the design included three components: 1) a core sampling of primary sampling units (metropolitan statistical areas and counties) and secondary sampling units (from continuous groupings of census blocks) with probability proportional to size, from which housing units and household members were sampled; 2) high-density supplemental sampling of census block groups in which the targeted ethnic groups made up more than $5 \%$ of the population; and 3) second respondent sampling to recruit participants from households where a primary respondent had already been interviewed. The response rates (calculated using the American Association for Public Opinion Research, Response Rate Method 3-or AAPOR-RR3 method) ${ }^{31}$ for primary and secondary respondents were $69 \%$ and $74 \%$, respectively. Sample weights were utilized to account for joint probabilities of selection for these three components and designed to allow the sample estimates to be nationally representative. ${ }^{31}$

Respondents were at least 18 years of age and resided in the U.S. Trained interviewers 
with linguistic and cultural backgrounds similar to those of the respondent, administered the survey with computer-assisted software in the respondent's chosen language (English, Cantonese, Mandarin, Tagalog, Vietnamese, or Spanish). Instruments were translated into these languages through standard techniques (translation of the instrument to a given language, followed by translation back to English for verification). Interviews were conducted face-to-face unless respondents requested a telephone interview. A further description of the NLAAS's data collection protocols is described elsewhere. ${ }^{32}$

The NLAAS sample comprised 2,095 persons; however, the $11.5 \%$ of the respondents who reported that they did not see a medical doctor in the past year were excluded from the sample. The sample $(\mathrm{N}=1,853)$ included $28.0 \%$ Chinese, $22.2 \%$ Filipino, 12.6\% Vietnamese, and 37.3\% “Other Asian Americans" (e.g., Indian, Japanese, Korean, Laotian). The proportions (weighted) of respondents who completed the interview in English were 52.7\% for Chinese, 89.2\% for Filipino, 24.3\% for Vietnamese, and 99.0\% for Other Asian Americans $(\mathrm{p}<.01)$. According to the U.S. Census 2000, the top three largest Asian ethnic groups in the U.S. included Chinese, Filipino, and Vietnamese. ${ }^{3}$

Sample characteristics (Table 1). The sample included 1,853 respondents. Nearly $55 \%$ of the respondents are female, $64 \%$ were employed, $90 \%$ had health insurance, and the mean age was 41.7 years. Most respondents were married or living with a partner (69.7\%), 22.1\% had never been married, and 8.3\% were divorced, separated, or widowed. Education levels varied, with $13.1 \%$ having less than a high school education, $17.2 \%$ being high school graduates, $25.3 \%$ having some college or more, and $44.4 \%$ having a college degree or more. The median household income was $\$ 62,500$ (mean $\$ 75,311$ ) and median household size was three members (mean 2.9). More than $16 \%$ of the respondents lived in poverty.

The majority of the respondents resided in the Western regions of the U.S. (68.0\%), followed by the Northeast (15.6\%), Midwest (8.7\%) and South (7.7\%). About a quarter of the sample was U.S.-born. Among immigrants, $12.3 \%$ of the respondents had lived in the U.S. for five years or less, $11.4 \%$ for $6-10$ years, $26.3 \%$ for $11-20$ years, and $25.2 \%$ for 20 years or more. About $69 \%$ of the sample reported having excellent or good Englishlanguage proficiency. Age at time of immigration varied with $12.3 \%$ immigrating at the age of 12 years or younger, $5.0 \%$ at $13-17$ years old, $41.6 \%$ at $18-34$ years, and $16.2 \%$ at 35 years old or older (the remaining respondents were U.S.-born). Three-quarters of the sample were first generation, $14.6 \%$ were second and $10.2 \%$ were third generation or later. Nearly $13 \%$ of the respondents had one or more past year mental/substance use disorder. The mean social desirability score was $7.8(\mathrm{se}=0.1)$.

The weighted proportion of respondents who reported that their medical doctor inquired about their mental health is $11.2 \%$.

Measures. Dependent variable. The study's outcome consisted of binary responses (yes/no) to the following question: In the past 12 months, did a medical doctor ask you about your emotions, nerves, or mental health?

Independent variables. Self-reported ethnicity included Chinese, Filipino, Vietnamese, and Other Asian Americans. Generational status was divided into three categories: first generation (i.e., respondent was an immigrant), second generation (i.e., respondent born in the U.S. and at least one parent was foreign-born), and third generation or later (both parents and the respondent were born in the U.S.). 


\section{Table 1.}

WEIGHTED SAMPLE CHARACTERISTICS OF

ASIAN AMERICANS: NATIONAL LATINO AND

ASIAN AMERICAN STUDY, 2002-2003

\begin{tabular}{|c|c|c|c|c|}
\hline & \multicolumn{4}{|c|}{ Provider Inquiry of Mental Health ${ }^{\mathrm{a}, \mathrm{b}}$} \\
\hline & & Yes & No & $p$ value \\
\hline Total sample (\#) & 1,853 & 199 & 1,654 & \\
\hline Weighted percentage & 100 & 11.2 & 88.8 & \\
\hline \multicolumn{5}{|l|}{ Ethnicity } \\
\hline Vietnamese & 12.6 & 7.3 & 92.7 & .01 \\
\hline Chinese & 28.0 & 11.8 & 88.2 & \\
\hline Filipino & 22.2 & 10.4 & 89.6 & \\
\hline Other Asian Americans & 37.3 & 12.6 & 87.4 & \\
\hline \multicolumn{5}{|l|}{$\operatorname{Sex}(\%)$} \\
\hline Female & 54.5 & 12.7 & 87.3 & .02 \\
\hline Male & 45.5 & 9.4 & 90.5 & \\
\hline Age, mean (SE) & $41.7(0.8)$ & $39.5(1.1)$ & $42.0(0.1)$ & .12 \\
\hline \multicolumn{5}{|l|}{ Marital status (\%) } \\
\hline Married/Cohabiting & 69.7 & 11.0 & 89.0 & .80 \\
\hline Divorced/Separated/Widowed & 8.3 & 12.8 & 87.2 & \\
\hline Never Married & 22.1 & 11.2 & 88.8 & \\
\hline \multicolumn{5}{|l|}{ Current health insurance (\%) } \\
\hline Yes & 90.0 & 11.7 & 88.3 & .15 \\
\hline No & 10.0 & 6.8 & 93.2 & \\
\hline \multicolumn{5}{|l|}{ Education (\%) } \\
\hline College or more & 44.4 & 12.0 & 88.0 & .30 \\
\hline Some college or more & 25.3 & 12.9 & 87.1 & \\
\hline High school & 17.2 & 7.4 & 92.3 & \\
\hline Less than high school & 13.1 & 10.5 & 89.5 & \\
\hline \multicolumn{5}{|l|}{ Employed (\%) } \\
\hline Yes & 63.7 & 10.9 & 89.1 & .68 \\
\hline Unemployed/Not in labor force & 36.3 & 11.8 & 88.2 & \\
\hline Household income (\$), mean (SE) & $75,311(2,376)$ & $80,841(5,262)$ & $74,612(2,457)$ & .25 \\
\hline \multicolumn{5}{|c|}{ Household income (\%) } \\
\hline$>\$ 100,000$ & 28.9 & 11.7 & 88.3 & .11 \\
\hline$\$ 65,000-\$ 100,000$ & 18.0 & 15.2 & 84.8 & \\
\hline$\$ 30,000-\$ 65,000$ & 27.3 & 10.2 & 89.8 & \\
\hline$<\$ 30,000$ & 25.9 & 9.1 & 90.0 & \\
\hline Household size, mean (SE) & $2.9(0.1)$ & $2.5(0.1)$ & $2.9(0.1)$ & $<.01$ \\
\hline Per capita income (\$), mean (SE) & $36,155(1,534)$ & $40,008(2,757)$ & $35,669(1,640)$ & .16 \\
\hline
\end{tabular}

(Continued on p. 1375) 
Table 1. (continued)

\begin{tabular}{|c|c|c|c|c|}
\hline & \multicolumn{4}{|c|}{ Provider Inquiry of Mental Health ${ }^{\mathrm{a}, \mathrm{b}}$} \\
\hline & & Yes & No & p value \\
\hline \multicolumn{5}{|l|}{ Poverty (\%) } \\
\hline Yes & 16.4 & 9.7 & 90.3 & \multirow[t]{2}{*}{.37} \\
\hline No & 83.6 & 11.5 & 88.5 & \\
\hline \multicolumn{5}{|l|}{ Region (\%) } \\
\hline Northeast & 15.6 & 11.7 & 88.3 & \multirow[t]{4}{*}{.08} \\
\hline Midwest & 8.7 & 14.4 & 85.6 & \\
\hline South & 7.7 & 18.2 & 81.8 & \\
\hline West & 68.0 & 9.9 & 90.1 & \\
\hline \multicolumn{5}{|c|}{ English-language proficiency (\%) } \\
\hline Excellent/good & 69.3 & 12.5 & 87.5 & \multirow[t]{2}{*}{.05} \\
\hline Fair/poor & 30.7 & 8.3 & 91.7 & \\
\hline \multicolumn{5}{|l|}{ U.S.-born (\%) } \\
\hline No & 75.2 & 15.9 & 84.1 & \multirow[t]{2}{*}{$<.01$} \\
\hline Yes & 24.8 & 9.7 & 90.3 & \\
\hline \multicolumn{5}{|l|}{ Years in the U.S. (\%) } \\
\hline $0-5$ & 12.3 & 12.4 & 87.6 & \multirow[t]{5}{*}{$<.01$} \\
\hline $6-10$ & 11.4 & 7.3 & 92.7 & \\
\hline $11-20$ & 26.3 & 10.6 & 89.4 & \\
\hline$\geq 20$ & 25.2 & 8.4 & 91.6 & \\
\hline U.S.-born & 24.8 & 15.9 & 84.1 & \\
\hline \multicolumn{5}{|c|}{ Age at time of immigration (years) } \\
\hline$(\%)$ & 24.8 & 15.9 & 84.1 & \multirow[t]{6}{*}{.08} \\
\hline U.S.-born & 12.3 & 12.3 & 87.7 & \\
\hline$\leq 12$ & 5.0 & 9.0 & 91.0 & \\
\hline $13-17$ & 41.6 & 7.9 & 92.1 & \\
\hline $18-34$ & 16.2 & 12.2 & 87.8 & \\
\hline$\geq 35$ & & & & \\
\hline \multicolumn{5}{|l|}{ Generational status (\%) } \\
\hline First & 75.2 & 9.7 & 90.3 & \multirow[t]{3}{*}{$<.01$} \\
\hline Second & 14.6 & 12.2 & 87.8 & \\
\hline Third or later & 10.2 & 21.2 & 78.8 & \\
\hline \multicolumn{5}{|l|}{ Has any mental/substance use } \\
\hline $\operatorname{disorder}^{\mathrm{c}}(\%)$ & 12.8 & 23.5 & 76.5 & \multirow[t]{3}{*}{$<.01$} \\
\hline Yes & 87.2 & 9.4 & 91.6 & \\
\hline No & & & & \\
\hline Social desirability, mean (SE) & $7.8(0.1)$ & $8.1(0.2)$ & $7.8(0.1)$ & .26 \\
\hline \multicolumn{5}{|c|}{$\begin{array}{l}\text { aPercentages might not equal } 100 \% \text { due to rounding. } \\
\text { ber the past } 12 \text { months, did a medical doctor ask you about your emotions, nerves, or mental health } \\
\text { (yes/no)? } \\
\text { cAssessed using the Diagnostic and Statistical Manual of Mental Disorders, Fourth Version (DSM-IV), } \\
\text { past } 12 \text { months. }\end{array}$} \\
\hline
\end{tabular}


The presence of any mental/substance use disorder within the past year was assessed using the World Health Organization Composite International Diagnostic Interview, ${ }^{33}$ a structured interview that follows the criteria of the Diagnostic and Statistical Manual of Mental Disorders, Fourth Edition (DSM-IV) ${ }^{34}$ and was designed to be administered by lay interviews. Any DSM-IV disorder included presence (yes/no) of the following disorders within the past 12 months: major depressive disorder, dysthymia, panic disorder, agroraphobia without panic, social phobia, generalized anxiety disorder, posttraumatic stress disorder, alcohol abuse, alcohol dependence, drug abuse, drug dependence, bulimia, anorexia, and panic disorder. Mental disorders were not separated from substance use disorders because having a substance use disorder increases the risk of having a mental disorder. ${ }^{35}$ Moreover, there was only a small proportion (1\%) of Asian Americans with a substance use disorder in the NLAAS sample.

Social desirability was assessed using nine items from the social desirability scale of the Zuckerman Personality Scales and a subset of the screening questions from the screening scale developed in conjunction with the International Personality Disorder Examination. ${ }^{36-43}$ Examples of such items include: "I never get annoyed when people cut ahead of me in line"; "I never get lost, even in unfamiliar places"; "I have always told the truth." Affirmative responses (yes/no) were summed. The total score range is $0-10$, with higher scores indicating more social desirability (Kuder-Richardson Formula $20=0.71$ ).

English language proficiency was assessed by the question, "How well do you speak English?" Responses were coded as excellent/good or fair/poor. Poverty was dichotomized as yes or no, to indicate whether the household income was below the federal poverty level for the corresponding family size in the year $2000 .^{44}$ Other sociodemographic characteristics were also assessed from the respondents: nativity status (U.S.-born/foreign-born), years lived in the U.S. (0-5, 6-10, 11-20, 20 or more), age at immigration in years (12 or younger, $13-17,18-34,35$ or older), current public/private health insurance (yes/no), sex, age (based on dates of birth and interview), marital status (married/cohabiting, divorced/separated/widowed, never married), current employment (yes or no/not in labor force), education (less than a high school diploma, high school graduate, some college education, and college graduate or beyond), household income, household size, per capita income, and region (Northeast, Midwest, South, West).

Analyses. Weighted descriptive statistics were computed for all Asian NLAAS respondents. The analyses accounted for the complex sample design when calculating appropriate standard error estimates.

The study outcome was medical doctors' inquiries on mental health in the past year (yes/no). Descriptive statistics were calculated to estimate population parameters. Bivariate analysis (for each explanatory variable; Wald tests used for evaluating statistical significance), and multiple logistic regressions (with adjustments for effect modification between ethnicity and mental/substance use disorders) were performed. The resulting multivariate model included age, sex, ethnicity, mental/substance use disorders, generational status, and social desirability - variables that were found to be significant in the bivariate analyses $(\mathrm{p}<.05)$, and/or variables that were found in previous research to be significantly associated with mental health services. Where possible, continuous measures were utilized; in other words, continuous data were not converted to categori- 
cal data. However, the analyses were restricted to the form the data were gathered in the survey. All analyses were performed using Stata $10.0^{45}$ and R 2.7.2. ${ }^{46}$

\section{Results}

Bivariate analyses (Table 2). Compared with first-generation respondents, the unadjusted odds ratios (OR) for Asian Americans' report of medical doctor inquiry of mental health was not significant for second but was significant for third-generation respondents (unadjusted $\mathrm{OR}=2.5$ ). Additionally, Filipino (unadjusted $\mathrm{OR}=1.7$ ) and Other Asian Americans (unadjusted $\mathrm{OR}=1.8$ ) had significantly higher odds of reporting medical doctors' inquiry of mental health than Vietnamese, however the similar observed difference between Chinese and Vietnamese only approached statistical significance.

Respondents with any mental/substance use disorder had nearly three times greater unadjusted odds of reporting that their medical doctor inquired about their mental health. Female respondents had 1.4 higher odds of reporting medical doctor inquiry of mental health compared with males.

\section{Table 2.}

BIVARIATE ANALYSES OF PATIENT-REPORTED MEDICAL DOCTOR OF MENTAL HEALTH AMONG ASIAN AMERICANS ${ }^{a}$

Bivariate OR [95\% CI]

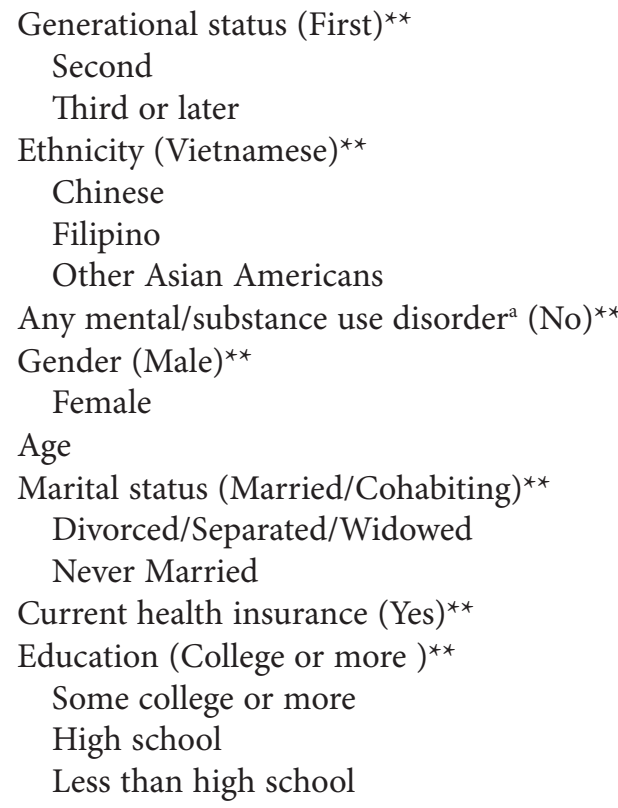

$1.29(0.81,2.07)$

$2.50(1.45,4.30)^{\star}$

$1.47(0.94,2.33)$

$1.69(1.11,2.58)^{*}$

$1.84(1.28,2.64)^{*}$

$2.95(2.02,4.32)^{*}$

$1.39(1.07,1.82)^{\star}$

$0.99(0.98,1.00)$

$1.19(0.67,2.09)$

$1.01(0.65,1.57)$

$0.55(0.24,1.25)$

$1.09(0.72,1.66)$

$0.58(0.30,1.14)$

$0.87(0.57,1.32)$

(Continued on p. 1378) 
Table 2. (continued)

Bivariate OR $[95 \% \mathrm{CI}]$

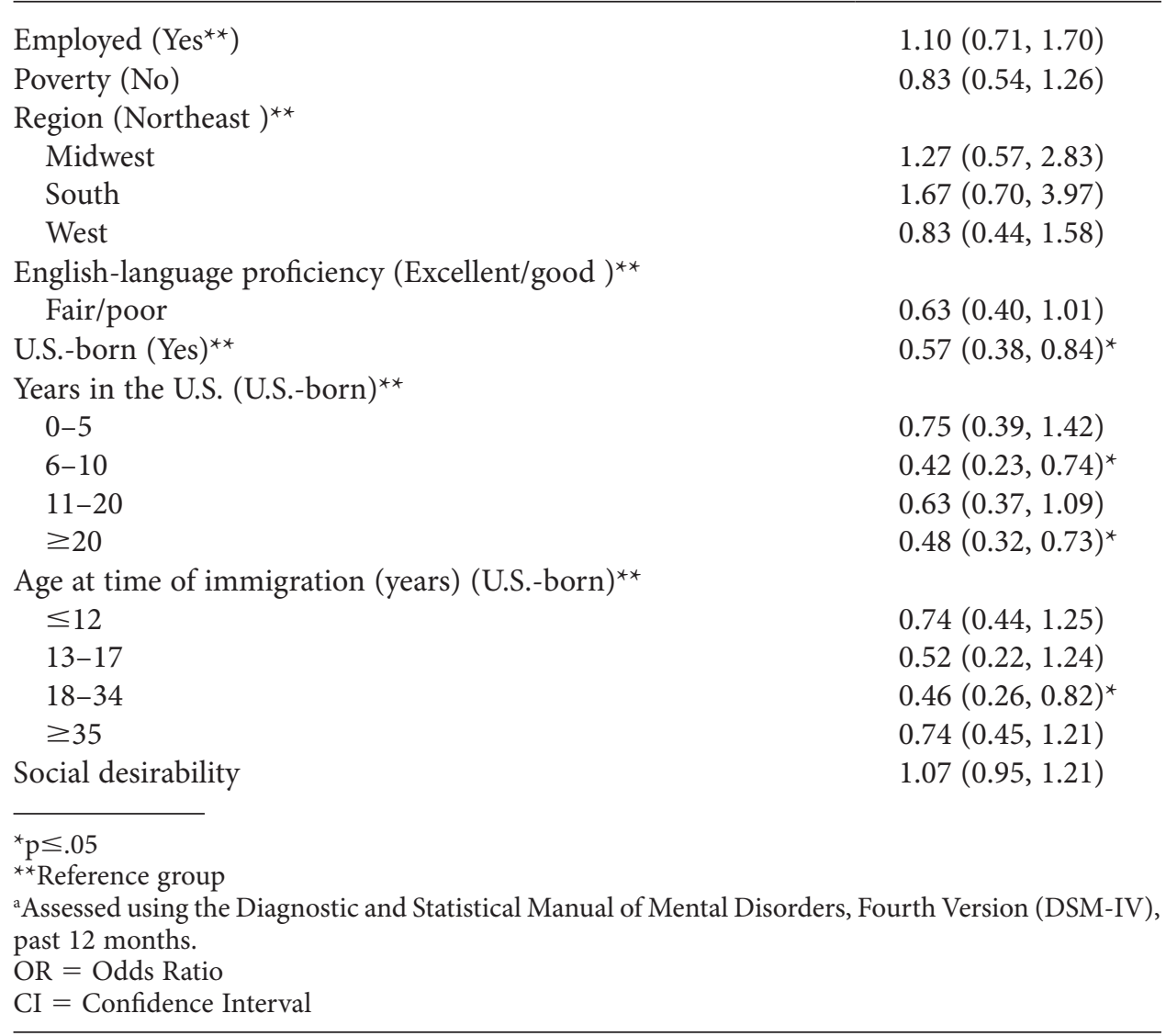

Non-U.S.-born respondents had significantly lower odds of reporting that their medical doctor inquired about their mental health compared with U.S.-born respondents (unadjusted $\mathrm{OR}=0.57$ ). Furthermore, respondents who lived in the U.S. for 6-10 or 20 or more years had significantly lower odds of reporting that their medical doctor inquired about their mental health than had U.S.-born respondents (unadjusted $\mathrm{OR}=0.42$; and, unadjusted $\mathrm{OR}=0.48$, respectively); however, this observed difference in odds was not significant when compared with respondents who lived in the U.S. 0-5 years or 11-20 years. Additionally, those who immigrated to the U.S. at 18-34 years old had significantly lower odds of reporting that their medical doctor had inquired about their mental health compared with U.S.-born respondents (unadjusted $\mathrm{OR}=0.46$ ); however, this association was not significant for respondents who immigrated at other ages.

There were no significant differences in Asian Americans' report of medical doctor inquiry of mental health by age, marital status, health insurance, education, employment, poverty, region of residence in the United States, English language proficiency, and social desirability. 
Multivariate analyses. Table $3 \mathrm{~A}$ presents results of a multivariate analysis of main effects. Asian Americans with U.S.-born parents had significantly greater odds compared to Asian Americans born outside the U.S. to report that their doctors inquired about their mental health $(\mathrm{OR}=2.15)$; though little difference was observed between Asian Americans born outside the U.S. and U.S.-born Asian Americans with non-U.S.-born parents.

Female respondents had 1.36 times greater odds of reporting that their doctors inquired about their mental health compared to males. No significant associations were found by age or by social desirability.

While the results in Table $3 \mathrm{~A}$ of the main effects model suggest significantly different odds of medical doctor inquiry depending on presence of a mental health or substance abuse disorder $(\mathrm{OR}=2.6)$, a closer examination of effects by the addition of an interaction term to the model (Table 3B) indicates a more subtle and complex determination of medical doctor inquiry. In the model with interactions presented, significant differences exist among ethnicities in the likelihood of provider inquiry about their mental health (as well as the other significant covariates indicated in the main effects model). However, the effects of mental health disorder are significantly modified by ethnicity (or equivalently, the effect of ethnicity on odds of provider inquiry significantly differs

\section{Table 3A.}

\section{MULTIVARIATE ANALYSES OF PATIENT-REPORTED MEDICAL DOCTOR INQUIRY OF MENTAL HEALTH AMONG ASIAN AMERICANS-MAIN EFFECTS MODEL ${ }^{a}$}

\begin{tabular}{lc}
\hline \hline & Multivariate OR [95\% CI] \\
\hline Generational status (First) ${ }^{* *}$ & \\
$\quad$ Second & $1.13(0.67,1.90)$ \\
$\quad$ Third or later & $2.15(1.26,3.68)^{\star}$ \\
Ethnicity (Vietnamese) ${ }^{* *}$ & $1.46(0.91,2.35)$ \\
$\quad$ Chinese & $1.30(0.79,2.13)$ \\
$\quad$ Filipino & $1.49(0.94,2.35)$ \\
$\quad$ Other Asian Americans & $2.60(1.76,3.85)^{\star}$ \\
Any mental/substance use disorder ${ }^{\mathrm{a}}(\mathrm{No})^{* *}$ & \\
Gender (Male) ${ }^{* *}$ & $1.36(1.04,1.79)^{\star}$ \\
$\quad$ Female & $0.99(0.98,1.01)$ \\
Age & $1.01(0.90,1.14)$ \\
Social desirability & \\
\hline${ }^{*} \leq .05$ & \\
${ }^{*}$ Reference group & \\
${ }^{a}$ Assessed using the Diagnostic and Statistical Manual of Mental Disorders, Fourth Version (DSM-IV), \\
past 12 months.
\end{tabular}


Table 3B.

MULTIVARIATE ANALYSES OF PATIENT-REPORTED

MEDICAL DOCTOR INQUIRY OF MENTAL HEALTH AMONG ASIAN AMERICANS-INTERACTION INCLUDED ${ }^{a}$

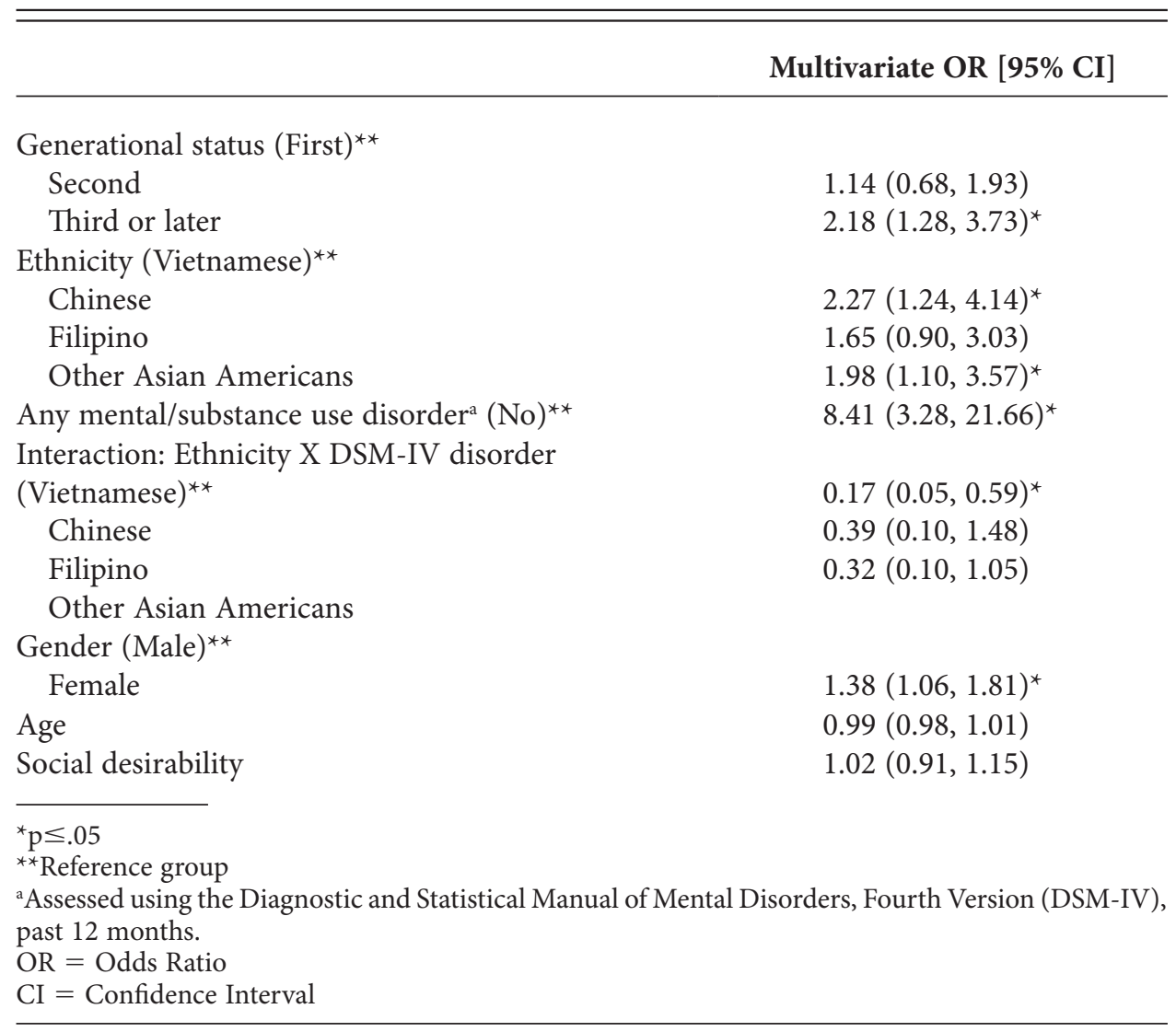

depending on the existence of previous year mental health/substance abuse disorder). As illustrated in Figure 1 (and presented in Table 3B), among those with no mental/ substance use disorder, all ethnicities had greater odds of reporting that their doctors inquired about their mental health than did the reference Vietnamese group. Any past year mental/substance use disorder increased the odds of Asian Americans reporting that their doctors inquired about their mental health status, although the magnitude of the increase varied widely depending on the ethnic group. The largest effect is observed among Vietnamese respondents with past year mental/substance use disorder, who had an estimated 8.4 times greater odds of reporting that they had received doctor inquiries than did their Vietnamese counterparts without a past year mental/ substance use disorder. Conversely, those odds within the Chinese group were only 1.4 times as great when comparing respondents with and without past year mental/ substance use disorder. 


\section{Discussion}

The study's objective was to examine factors influencing the likelihood of Asian Americans' report of being inquired by their doctors about their mental health. It was found that Asian Americans' report of medical doctor's inquiries about mental health do vary in this population with generational status, ethnicity, and/or presence of mental/ substance use disorder(s). Specifically, two major findings result from the study. First, Asian Americans with U.S.-born parents had odds twice as great as those of Asian Americans born outside the U.S. of reporting that their doctors inquired about their mental health; hence, the hypothesis that recent immigrants would be less likely to report that their doctors asked about their mental health compared to others was supported.

Second, results show that among those with any mental/substance use disorder in the past 12 months, the odds of reporting that one was asked about one's mental health are highest among Vietnamese. These findings remain after adjustment for potential confounders including age, gender, generational status and social desirability. Contrary to the authors' hypothesis, it is striking that having a mental/substance use disorder in the past 12 months affected the likelihood of reporting that a medical doctor asked about the mental health among Chinese less than it did among Vietnamese. The interaction of any mental/substance use disorder in the past 12 months and ethnicity is substantial; having a previous mental/substance use disorder in the past 12 months changes the odds of reporting about being inquired differently depending on the ethnicity. This

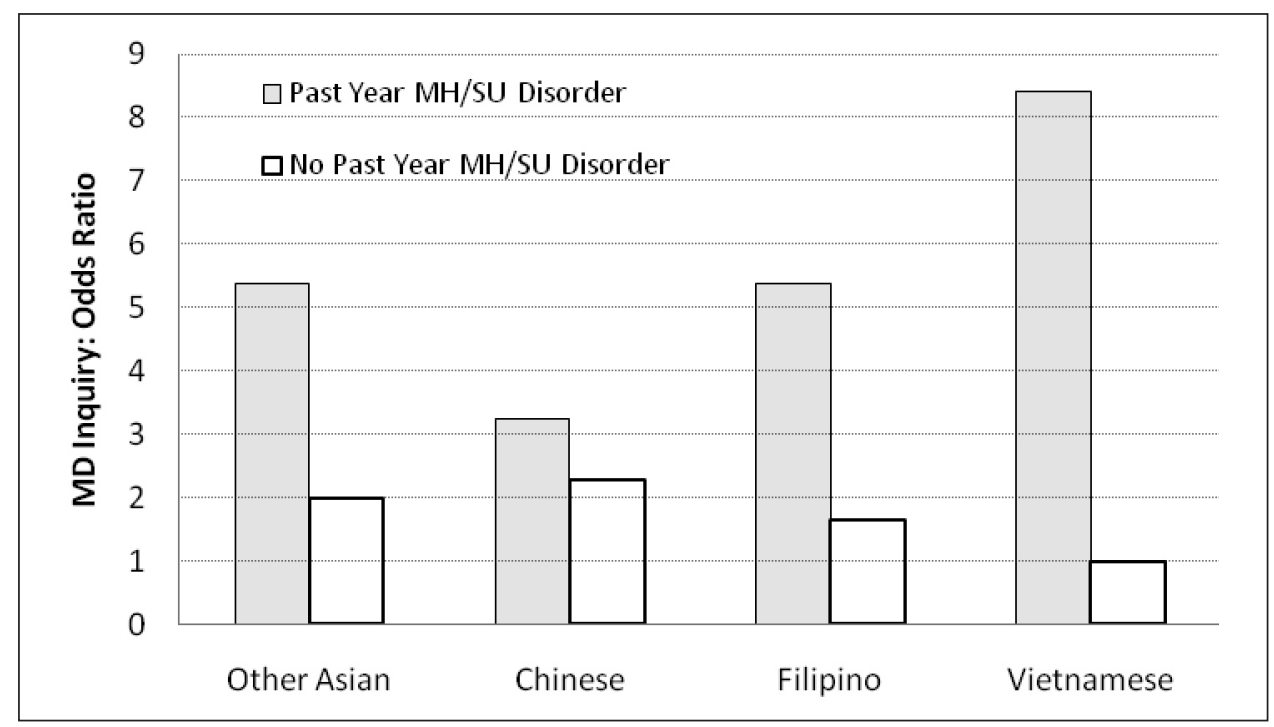

Figure 1. An illustration of the estimated odds ratios based on a multivariate model, adjusted for generational status, gender, age and social desirability. Reference group: Vietnamese with no past year MH/SU disorder.

$\mathrm{MD}=$ Medical doctor

MH $=$ Mental health

$\mathrm{MH} / \mathrm{SU}=$ Mental health/substance use 
study suggests that additional research in this area needs to be conducted to better understand why screening differs by ethnicity and mental health status.

An example of an area that requires further exploration is patient-provider concordance, which is defined as "a state of agreement or harmony" 7 [p.3] between the patient and the provider in various characteristics such as race and language. Cooper and Powe reported that health care disparities are persistent among racial and ethnic minorities, and research "links patient-physician race and ethnic concordance with higher patient satisfaction and better health care processes." ${ }^{4[p . i i]}$ Indeed, research suggests that patients who are race-concordant with their medical providers generally report higher satisfaction with their providers along with higher ratings of care. ${ }^{48,49}$ However, research among Asian Americans is limited; therefore, additional research is needed including those examining the extent to which racial, ethnic and/or language concordance between the provider and patient play a role in the likelihood that a medical provider would inquire about a patient's mental health especially among recent immigrants. For example, it is plausible that Vietnamese individuals with a mental/substance use disorder are more likely to be screened for mental health by a medical doctor because the medical doctor is also Vietnamese; thus, there is racial/ethnic concordance between the patient and provider which may be important in that language, for instance, does not serve as a communication barrier to ask about one's mental health.

An additional important question to include is to what extent does the role of patientprovider racial, ethnic and language concordance affect the likelihood of Asian American patients disclosing mental health needs to their medical doctors? Unfortunately, this study was limited in its ability to explore these questions because there were no data regarding the medical doctors' racial, ethnic or language background; however, the primary author of this study does have a study in its early stage exploring these questions.

As mentioned earlier, it is important to understand the pathways to mental health/ substance use services utilization especially among populations that underutilize mental health/substance use services. This study is particularly relevant because it investigates the relative roles of generational status, ethnicity and mental/substance use disorder in patients' self-reports about a doctor asking them about their mental health-one of the pathways to the use of mental health services. The study results indicate that patients' reports of medical doctors' inquiry of mental health do differ by these factors. Future research should examine whether the medical doctors' responses to this question are similar to the patients' responses in order to determine whether the results are a difference in perception or reflect what actually happened.

Furthermore, this study is particularly significant and timely given its relevance to the 2010 Patient Protection and Affordable Care Act. This legislation stipulates that individuals can access preventive services for free (in other words, with no cost-sharing) through their health plans, effective September 23, 2010 for new insurance plans (January 1, 2011 for many plans). ${ }^{50}$ Among the covered preventive services for adults are depression screening and alcohol misuse screening and counseling.

It is assumed that given this new mandate, there will be an increase in the number of adult patients who will be screened for depression and alcohol use. However, future research should investigate whether the rates of depression and alcohol misuse screening will be observed similarly across ethnic groups and generational status. For example, 
although it is speculated that Asian Americans as a group may benefit from this law, it is unknown to what extent providers are adequately trained to inquire about depression and alcohol use among Asian American patients and, if asked, whether the patients will even disclose their depression status and alcohol use due to culturally salient factors such as fear of loss of face, as previously discussed. Moreover, though the provision of free depression screening and alcohol misuse screening and counseling are applauded, it is yet to be determined whether (1) Asian American patients screened to be depressed and/or misuse alcohol will actually accept their diagnosis and seek treatment; (2) there are additional financial barriers to accessing treatment because there may exist cost-sharing for depression treatment; and, (3) the health care system is equipped to care for this patient population that has conventionally not received such services. As noted previously, effective mental health treatments exist; however, the questions about whether such treatments are available in the appropriate languages and culturally competent remain. It would be unethical to advocate for universal screening if treatment is indeed unavailable for culturally diverse populations such as Asian Americans. Finally, it should be noted that this new legislation does not include free screening for other mental/substance use disorders; thus, there still exists a segment of a population that may potentially be missed in terms of screening and therefore treatment not accessed.

These study findings should be interpreted with the following limitations in mind. First, the NLAAS is a cross-sectional study, thus, it is plausible that certain Asian Americans with mental disorders are seeking out care and/or selecting those medical doctors who are likely to inquire more about their mental health. One could better understand these relations by including in interviews with Asian Americans, inquiries about their medical history, including their pattern of selection of medical doctors (e.g., referral source, if any). Second, these findings can only be generalized to non-institutionalized, non-homeless Asian Americans. Third, it is possible that self-reporting bias exists in the NLAAS data responses, although the authors attempted to mitigate this possibility by controlling for social desirability in the analyses.

This study also has strengths. First, to the authors' knowledge, this is the first study to investigate empirically the associations among ethnicity, generation, and mental/ substance use disorders in self-reported medical doctors' of mental health among a nationally representative, large sample of Asian Americans. Moreover, because NLAAS was administered using standardized instruments it will be possible to compare these study findings with results of future studies, including those examining other racial/ ethnic groups.

\section{Acknowledgments}

This research was supported by a Faculty Fund for Research Project Development Award from the University of Hawai'i at Mānoa, Office of Public Health Studies.

\section{Notes}

1. Herrick CA, Brown HN. Underutilization of mental health services by Asian-Americans residing in the United States. Issues Ment Health Nurs. 1998 May-Jun;19(3):225-40. 
2. Abe-Kim J, Takeuchi DT, Hong S, et al. Use of mental health-related services among immigrant and US-born Asian Americans: results from the National Latino and Asian American Study. Am J Public Health. 2007 Jan;97(1):91-8.

3. Reeves TJ, Bennett CE. We the people: Asians in the United States: Census 2000 Special Reports. Washington, DC: U.S. Census Bureau, 2004 Dec. Available at: http://www .census.gov/prod/2004pubs/censr-17.pdf.

4. Snowden LR, Masland MC, Peng CJ, et al. Limited English proficient Asian Americans: threshold language policy and access to mental health treatment. Soc Sci Med. 2011 Jan;72(2):230-7.

5. Spencer MS, Chen J, Gee GC, et al. Discrimination and mental health-related service use in a national study of Asian Americans. Am J Public Health. 2010 Dec;100 (12):2410-7.

6. Le Meyer O, Zane N, Cho YI, et al. Use of specialty mental health services by Asian Americans with psychiatric disorders. J Consult Clin Psychol. 2009 Oct;77(5):1000-5.

7. Chen HJ. Mental illness and principal physical diagnoses among Asian American and Pacific Islander users of emergency services. Issues Ment Health Nurs. 2005 Dec; 26(10):1061-79.

8. Yeung A, Yu SC, Fung F, et al. Recognizing and engaging depressed Chinese Americans in treatment in a primary care setting. Int J Geriatr Psychiatry. 2006 Sep;21(9):819-23.

9. World Health Organization. Constitution of the World Health Organization as adopted by the International Health Conference, 1946. New York, NY: World Health Organisation, 1948. Available at: http://www.who.int/governance/eb/who_constitution_en.pdf.

10. Klinkman MS. Competing demands in psychosocial care: a model for the identification and treatment of depressive disorders in primary care. Gen Hosp Psychiatry. 1997 Mar;19(2):98-111.

11. Nease DE Jr, Klinkman MS, Aikens JE. Depression case finding in primary care: a method for the mandates. Int J Psychiatry Med. 2006;36(2):141-51.

12. Pignone MP, Gaynes BN, Rushton JL, et al. Screening for depression in adults: a summary of the evidence for the U.S. Preventive Services Task Force. Ann Intern Med. 2002 May;136(10):765-76.

13. Gilmer TP, Ojeda VD, Folsom DP, et al. Initiation and use of public mental health services by persons with severe mental illness and limited English proficiency. Psychiatr Serv. 2007 Dec;58(12):1555-62.

14. U.S. Preventive Services Task Force. Screening for depression: recommendations and rationale. Ann Intern Med. 2002 May;136(10):760-64.

15. Mulrow CD, Williams JW Jr, Chiquette E, et al. Efficacy of newer medications for treating depression in primary care patients. Am J Med. 2000 Jan;108(1):54-64.

16. Barry DT, Grilo CM. Cultural, psychological, and demographic correlates of willingness to use psychological services among East Asian immigrants. J Nerv Ment Dis. 2002 Jan;190(1):32-9.

17. Hsu L, Alden LE. Cultural influences on willingness to seek treatment for social anxiety in Chinese- and European-heritage students. Cultur Divers Ethnic Minor Psychol. 2008 Jul;14(3):215-23.

18. Kung WW, Lu PC. How symptom manifestations affect help seeking for mental health problems among Chinese Americans. J Nerv Ment Dis. 2008 Jan;196(1):46-54.

19. Chung H, Teresi J, Guarnaccia P, et al. Depressive symptoms and psychiatric distress in low income Asian and Latino primary care patients: prevalence and recognition. Community Ment Health J. 2003 Feb;39(1):33-46. 
20. Ta VM, Juon HS, Gielen AC, et al. Disparities in use of mental health and substance abuse services by Asian and Native Hawaiian/other Pacific Islander women. J Behav Health Serv Res. 2008 Jan;35(1):20-36.

21. Ta VM, Holck P, Gee GC. Generational status and family cohesion effects on the receipt of mental health services among Asian Americans: findings from the National Latino and Asian American Study. Am J Public Health. 2010 Jan;100(1):115-21.

22. Dudley NM, McFarland LA, Goodman SA, et al. Racial differences in socially desirable responding in selection contexts: magnitude and consequences. J Pers Assess. 2005 Aug;85(1):50-64.

23. Lalwani AK, Shavitt S, Johnson T. What is the relation between cultural orientation and socially desirable responding? J Pers Soc Psychol. 2006 Jan;90(1):165-78.

24. Yip T, Gee GC, Takeuchi DT. Racial discrimination and psychological distress: the impact of ethnic identity and age among immigrant and United States-born Asian adults. Dev Psychol. 2008 May;44(3):787-800.

25. Gee G, Spencer M, Chen J, et al. The association between self-reported discrimination and 12-month DSM-IV mental disorders among Asian Americans nationwide. Soc Sci Med. 2007 May;64(10):1984-96.

26. DeNavas-Walt C, Proctor BD, Smith JC. Income, poverty, and health insurance coverage in the United States: 2009.Washington, DC: U.S. Census Bureau, 2010 Sep; 60-236. Available at: http://www.census.gov/prod/2010pubs/p60-238.pdf.

27. Austin A, Kim M. Stuck in neutral: economic gains stall out for Asian Americans and Pacific Islanders in the 2000s. Washington, DC: Economic Policy Institute, 2009. Available at: http://www.epi.org/page/-/pdf/bp228.pdf?nocdn=1.

28. Kim C. The racial triangulation of Asian Americans. Politics and Society. 1999 Mar; 27(1):105-38.

29. Reeves T, Bennett C. The Asian and Pacific Islander population in the United States: March 2002. Washington, DC: U.S. Census Bureau, 2003; 20-540. Available at: http:// www.census.gov/prod/2003pubs/p20-540.pdf.

30. Alegria M, Vila D, Woo M, et al. Cultural relevance and equivalence in the NLAAS instrument: integrating etic and emic in the development of cross-cultural measures for a psychiatric epidemiology and services study of Latinos. Int J Methods Psychiatr Res. 2004;13(4):270-88.

31. Heeringa SG, Wagner J, Torres M, et al. Sample designs and sampling methods for the collaborative psychiatric epidemiology studies (CPES). Int J Methods Psychiatr Res. 2004;13(4):221-40.

32. Pennell BE, Bowers A, Carr D, et al. The development and implementation of the national comorbidity survey replication, the national survey of American life, and the national Latino and Asian American survey. Int J Methods Psychiatr Res. 2004; 13(4):241-69.

33. World Health Organization. Disability assessment schedule II (WHO-DAS II). Training manual: a guide to admistration. Geneva, Switzerland: World Health Organization, 2000. Available at: http://www.who.int/icidh/whodas/training_man.pdf.

34. American Psychiatric Association. Diagnostic and statistical manual of mental disorders, DSM-IV (4th ed.). Washington, DC: American Psychiatric Association, 1994.

35. Schulden JD, Thomas YF, Compton WM. Substance abuse in the United States: findings from recent epidemiologic studies. Curr Psychiatry Rep. 2009 Oct;11(5):353-9.

36. Zuckerman M, Link K. Construct validity for the sensation-seeking scale. J Consult Clin Psychol. 1968 Aug;32(4):420-6. 
37. Zuckerman M, Eysenck S, Eysenck HJ. Sensation seeking in England and America: cross-cultural, age, and sex comparisons. J Consult Clin Psychol. 1978 Feb;46(1):139-49.

38. Zuckerman M, Kuhlman DM. Personality and risk-taking: common biosocial factors. J Pers. 2000 Dec;68(6):999-1029.

39. Zuckerman M, Bone RN, Neary R, et al. What is the sensation seeker? Personality trait and experience correlates of the sensation-seeking scales. J Consult Clin Psychol. 1972 Oct;39(2):308-21.

40. Zuckerman M. Behavioral expressions and biosocial bases of sensation seeking. New York, NY: Cambridge University Press, 1994.

41. Zuckerman M. Psychobiology of personality. Cambridge, United Kingdom: Cambridge University Press, 1991.

42. Loranger AW, Sartorius N, Andreoli A, et al. The international personality disorder examination: the World Health Organization/Alcohol, Drug Abuse, and Mental Health Administration international pilot study of personality disorders. Arch Gen Psychiatry. 1994 Mar;51(3):215-24.

43. Loranger A, Janca A, Sartorius N, eds. Assessment and diagnosis of personality disorders: the ICD-10 International Personality Disorder Examination (IPDE). New York, NY: Cambridge University Press, 1997.

44. U.S. Census Bureau. Poverty thresholds 2000: size of family and number of related children under 18 years. Washington, DC: U.S. Census Bureau, 2010. Available at: http://www.census.gov/hhes/www/poverty/threshld/thresh00.html.

45. Stata Corporation. Stata statistical software: release 10.0 (computer program). College Station, TX: Stata Corporation, 2007.

46. R Foundation for Statistical Computing. R: a language and environment for statistical computing (computer program). Vienna, Austria: R Foundation for Statistical Computing, 2008.

47. Cooper LA, Powe NR. Disparities in patient experiences, health care processes, and outcomes: the role of patient-provider racial, ethnic, and language concordance. New York, NY: The Commonwealth Fund, 2004 Jul. Available at: http://www.common wealthfund.org/programs/minority/cooper_raceconcordance_753.pdf.

48. Cooper LA, Roter DL, Johnson RL, et al. Patient-centered communication, ratings of care, and concordance of patient and physician race. Ann Intern Med. 2003 Dec; 139(11):907-15.

49. Laveist TA, Nuru-Jeter A. Is doctor-patient race concordance associated with greater satisfaction with care? J Health Soc Behav. 2002 Sep;43(3):296-306.

50. U.S. Department of Health and Human Services. Preventive services covered under the Affordable Care Act. Washington, DC: U.S. Department of Health and Human Services, 2010. Available at: http://www.healthcare.gov/law/about/provisions/services /lists.html. 